\title{
Estimation of cost savings from participation of electric vehicles in vehicle to grid (V2G) schemes
}

\author{
Mahdi KIAEE ( $\triangleleft)$, Andrew CRUDEN, \\ Suleiman SHARKH
}

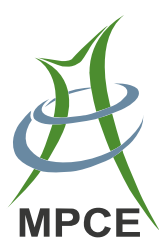

\begin{abstract}
The storage capacity of the batteries in an electric vehicle (EV) could be utilised to store electrical energy and give it back to the grid when needed by participating in vehicle to grid (V2G) schemes. This participation could be a source of revenue for vehicle owners thus reducing the total charging cost of their EVs. A V2G simulator has been developed using MATLAB to find out the potential cost saving from participation of EVs in V2G schemes. A standard IEEE30 network has been modelled in the simulator which uses the MATPOWER engine to undertake power flow analysis. A novel control algorithm has been developed to take advantage of the difference between the selling and buying electricity prices by charging and discharging EVs at the appropriate time. Two scenarios are simulated to compare the total charging cost of EVs with or without the utilisation of V2G technology within the power system assuming a total of $5000 \mathrm{EVs}$. The results of the simulation show that the applied control strategy with $\mathrm{V} 2 \mathrm{G}$ is able to reduce the charging cost of EVs by $13.6 \%$ while satisfying the minimum requirement for state of charge (SoC) of the EV batteries to complete their next journey.
\end{abstract}

Keywords Electric vehicles, Cost saving, Electricity price, Vehicle to grid

CrossCheck date: 15 April 2015

Received: 21 October 2014/Accepted: 17 April 2015/Published online: 14 May 2015

(C) The Author(s) 2015. This article is published with open access at Springerlink.com

M. KIAEE, A. CRUDEN, S. SHARKH, Energy Technology

Research Group, Engineering Sciences, University of

Southampton Highfield Campus, Southampton SO17 1BJ, UK

$(\bowtie)$ e-mail: M.Kiaee@ soton.ac.uk

\section{Introduction}

Electric vehicles (EVs) are predicted to be one of the main clean transport options in the future [1]. In addition to lowering the amount of greenhouse gas emissions, these vehicles can increase energy efficiency and reduce oil imports [2].

However, due to the additional demand that these EVs impose on the power system, they could cause many problems for grid operators if a significant number of them charges simultaneously. In places where the grid is close to its capacity limits, more investment should be envisaged to reinforce the network infrastructure.

The energy stored in EV batteries is normally used for powering the vehicle, but it could also be fed back into the grid when electricity prices are high to potentially make some profit for the EV owner if they are rewarded from the grid for the service. The concept of injecting power back into the grid from EV batteries is known as vehicle-to-grid (V2G) [3]. Automobiles are on average parked $96 \%$ of the time which increases the chance of them being available and connected for V2G operation [4]. Therefore, by using smart controllers, these vehicles could be charged when the price of electricity is low and give some energy back to the grid when the price of electricity is high if their stored energy is higher than the immediate transport requirement of the vehicle owner.

Some relevant work has been done to study other researchers on the impact of $\mathrm{V} 2 \mathrm{G}$ on the grid and the benefit of V2G participation for the vehicle owners. Sierzchula et al. [1] have explored the relationship between financial incentives and other socio-economic factors to the adoption of EVs in several countries. They found that financial incentives, charging infrastructure, and local presence of an EV manufacturing facility can significantly affect a country's electric vehicle market share [1]. Pieltain et al. [5] 
have proposed a way to evaluate the impact of plug-in electric vehicles (PEVs) on the energy loss and investment of distribution network. Clement et al. [6, 7] have shown that uncoordinated charging of plug-in hybrid electric vehicles (PHEVs) in distribution network can lead to local grid problems, and therefore they proposed a coordinated charging and discharging approach to minimize the power losses and maximize the load factor within the system.

Ma et al. [8] have proposed a control strategy to charge/ discharge EVs by considering the electricity price. They compared the results from two scenarios: with and without V2G operation. However, they considered neither vehicle movements within the system, nor the difference in the SoC of EV batteries in the 'With V2G' and 'Without V2G' scenarios at the end of the simulations. This has led to an inaccurate estimation of savings from $V 2 \mathrm{G}$ participation of EVs. In addition, their simulation is only carried out for one day, which is not long enough for the modelled system to reach steady state condition. Zhong [9] has proposed a distributed framework for demand response and user adaptation in smart grid networks by using the concept of congestion pricing in internet traffic control. They showed that pricing information is very useful for regulating user demand and balancing the network load. Further research work reported in [10-13] also investigated the potential use of EV aggregators in different electricity markets.

This paper investigates the utilisation of EVs as an electrical energy store to take advantage of the difference between the selling and buying electricity price to reduce the cost of charging EVs by selling some electricity back to the grid during high electricity price and buying electricity from the grid during the times when the electricity price is low. This paper proposed a novel dispatching strategy which is applied to the system for the charging and discharging of parked EVs within the IEEE30 [14] network while considering their capacity, state of charge $(\mathrm{SoC})$, vehicle movement within the system, the electricity prices and the requirements of the driver and power system operator.

\section{Methodology}

Software was developed by the authors using MATLAB and MATPOWER [15] to simulate the standard IEEE30 model with 5000 EVs.

Two scenarios are modelled in the simulations and are listed below.

1) 'Without V2G' scenario: The simulator uses the control strategy to only charge EVs when 'parked' within the network.

2) 'With V2G' scenario: The simulator applies the control strategy to charge and discharge EVs when 'parked' within the network.

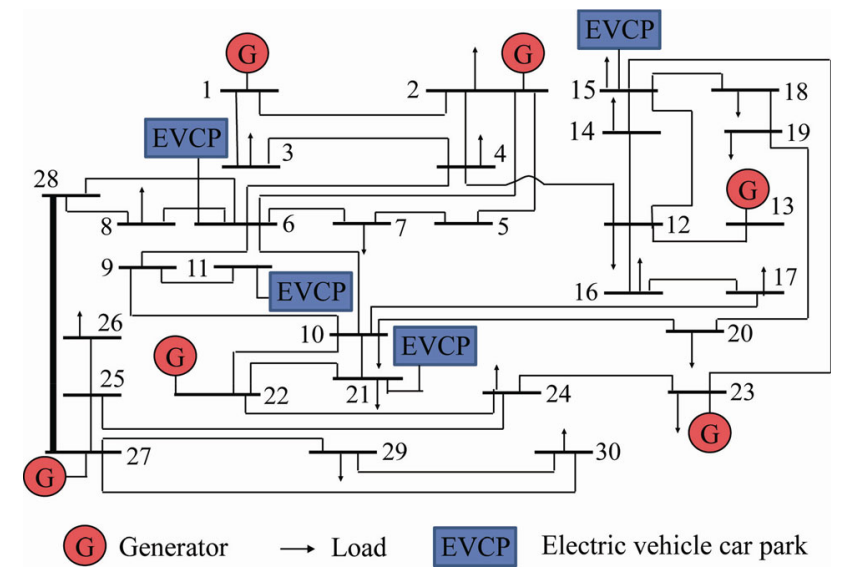

Fig. 1 IEEE30 power system with EV car parks added to four different buses

Figure 1 shows the standard IEEE30 model used in the simulation. It has 30 buses and a total of six generation plants. As detailed in Table 1, four EV multi storey car parks accommodating $4000 \mathrm{EVs}$ in total, are added on four buses of this grid. In addition to these car parks, $1000 \mathrm{EVs}$ are randomly scattered within the network without going into the car parks during the simulation.

\subsection{Main assumptions for the analysis}

To carry out the analysis for the system under investigation, the following assumptions were made by the authors.

It is assumed that each EV consumes only active power. When the EVs are being charged, they consume $3 \mathrm{~kW}$ through 13A converters and when discharged they inject the same power level back into the grid. The nominal capacities of all EVs are assumed to be equal at a capacity selected by the user.

All of the parked EVs are assumed connected to the grid and are able to be instructed by the control centre to be charged or discharged if they participate in V2G scheme. This means that there exists a robust and reliable communication system between the grid control centre and each parked vehicle. This system sends some information about the EV to the control centre and receives the instruction from the control centre about the EV's role in the system.

\subsection{EV movements within the network}

The EVs are not stationary and move to different places during a day. However, during weekdays, EVs which belong to the working people normally have a predictable driving pattern, where it is assumed that they normally drive to work and back home at certain time of the day. The 
Table 1 Car park details

\begin{tabular}{llll}
\hline $\begin{array}{l}\text { Car park } \\
\text { number }\end{array}$ & $\begin{array}{l}\text { Location } \\
\text { (bus number) }\end{array}$ & $\begin{array}{l}\text { Maximum number } \\
\text { of EVs in the } \\
\text { car park }\end{array}$ & $\begin{array}{l}\text { Rating } \\
\text { (MW) }\end{array}$ \\
\hline 1 & 6 & 1300 & 3.9 \\
2 & 11 & 700 & 2.1 \\
3 & 15 & 500 & 1.5 \\
4 & 21 & 1500 & 4.5 \\
\hline
\end{tabular}

EV owners go to work in the morning during the weekdays and return home sometime in the afternoon.

It is assumed that some EVs are randomly scattered on different buses within the grid, but most EVs are parked inside car parks. For each randomly scattered EV, it is assumed that the workplace and home of the EV owners are on two random different buses of the power system. The randomly scattered EVs do not go into car parks, but they can appear on a bus connected to an EV multi-storey car park.

On the other hand, the EVs are assumed to be parked in their allocated car park spaces when the EV owner is at work, but when the owner goes home, the simulator treats it as a normal randomly scattered EV. This means that the software allocates a random bus, which is different from its workplace (or the car park bus), to each EV for its home location. It should be noted that the workplace and home location of each EV owner do not change during the simulation.

The simulator allocates the same travel pattern with the same timing to each EV for all simulation days, but different vehicles have different start and duration time for their daily journey. Each EV travels from home to work at a random but constant time between $7 \mathrm{am}$ and 10am every day. The travel duration of each EV is a random time between 10 minutes to 1.5 hours with a resolution of 10 minutes. The 'Work to home' journey of each EV starts at a random time between $4 \mathrm{pm}$ to $6 \mathrm{pm}$ with 10 minute resolution.

\subsection{Calculation of state of charge (SoC)}

The simulator does not change the SoC of the EV batteries when the EV is parked and not instructed by the control centre to be charged or discharged.

The simulator accepts a minimum and maximum SoC limit for the EV batteries. This minimum SoC limit selected by the user is the absolute minimum value which should not be reached even at the end of a journey, and it is the same for all of the EVs within the system. Therefore, the simulator has to find another secondary minimum SoC limit for each EV based on the amount of energy it consumes during its next journey to make sure that the EV batteries do not reach this limit. In the control strategy, the simulator uses this secondary limit which is not necessarily the same value for all EVs. Obviously, this secondary minimum SoC limit is higher than the initial minimum SoC and does not vary during the simulation because the distance each EV travels in all of its journeys ('Home to work' or 'Work to home') is equal and constant during the simulation.

At the start of the simulation, the software gives a random initial SoC between the minimum and maximum SoC limits to each EV used for the first time interval.

As the duration of 'Home to work' or 'Work to home' journeys for each vehicle are assumed to be the same and the vehicles are assumed to have constant weight, speed and route in both of their journeys, the energy $(\mathrm{kWh})$ consumed by each EV in any of its journeys are assumed to be the same each day. To find this energy consumption the simulator assumes that each EV travels during a commute with the average speed of $20 \mathrm{miles} / \mathrm{h}$ [16] and on average it consumes $0.25 \mathrm{kWh}$ energy per mile it travels [17]. All of batteries in an EV are modelled with one battery in this paper. Therefore, when an EV is moving the SoC of its battery reduces according to the following equation after each simulation time step (10 minutes or $1 / 6$ of an hour):

$\operatorname{SoC}_{E V_{i}}^{t+1}=\operatorname{SoC}_{E V_{i}}^{t}-\frac{\bar{v} \times \bar{E}}{C} \times \delta \times 100$

where $t$ is the time interval (each one represents 10 minutes during the simulation); $S o C_{E V_{i}}^{t}$ is the SoC of the battery of the $i^{\text {th }} \mathrm{EV}$ in percentage at the time interval $t ; \bar{E}$ is the average energy consumed by each vehicle in $\mathrm{kWh} / \mathrm{mile} ; \bar{v}$ is the average speed of each vehicle in mile/hour; $C$ is the capacity of the battery in each $\mathrm{EV}$ in $\mathrm{kWh}$; and $\delta$ is the time interval of the simulation which is $1 / 6$ of an hour.

In addition, when an EV is parked and being charged or discharged the simulator uses the following equation to calculate the change in the SoC of the EV batteries after each time step:

$S o C_{E V_{i}}^{t+1}=S o C_{E V_{i}}^{t}+\mathrm{Z} \frac{R}{C} \times \delta \times 100$

where $Z$ is equal to 1 when the $\mathrm{EV}$ is charging and equal to -1 when it is discharging the energy stored its batteries back to the grid and $R$ is the rate of charging or discharging of the EVs.

\subsection{Simulator inputs}

Table 2 shows some inputs entered into the simulator before starting the simulation.

As shown in Table 3, the user of the simulator can select the time that the vehicles are allowed to charge or discharge during each hour of a day. These values are selected 
Table 2 Input data for the simulator

Number of randomly scattered EVs within the power system 1000

Nominal capacity of each EV (C) (kWh)

Minimum SoC limit (Min_SoC) of each EV (\%)

Maximum SoC limit (Max_SoC) of each EV (\%)

based on the requirements of the power system operators and the EV owners. For example, in Table 3 charging is allowed from 5 am to 6 am because the total non-EV demand on the system is not high then, but $\mathrm{V} 2 \mathrm{G}$ participation is not allowed at that time of the day because the vehicle owners might not want to participate in V2G just before travelling to work in the morning.

As it will be explained further in Section 2.5, the user selection in Table 3 to avoid charging or discharging at certain time has higher priority than the applied control strategy, unless the vehicle has a low SoC below the minimum limit, in which case the $\mathrm{EV}$ will be charged immediately after it is plugged into the system to reach its minimum SoC limit without considering any other limitation because satisfying the minimum energy requirement for the next journey of the owner has higher priority than anything else.

It is worth mentioning that that the simulator converts the inputs in Table 3 to 10 min resolution data by assuming that they are constant during each hour.

\subsection{Control strategy based on electricity price}

In this section the control strategy used to make decisions about the time that the EVs should be charged or discharged is explained. To achieve the goal of taking advantage of the difference in the electricity buying and selling price the following algorithm is applied to the system with a time resolution of 10 minutes.

The flowcharts in Fig. 2 and Fig. 3 show the algorithm and the control strategy used by the simulator at each time interval to make decision about charging or discharging of EVs within the system. At each time step of the simulation, the simulator looks at the SoC of all of the EVs within the system, and if an EV is travelling, then its battery SoC will be reduced by the simulator using (1), but if it is being parked and plugged in to the grid the simulator implements the following control strategy to determine what happens to each EV in either 'With V2G' or 'Without V2G' scenarios.

1) In the first stage of the control strategy, the simulator finds the EVs which have SoC below their minimum limit in both with and without V2G scenarios, and it charges their batteries without considering any other criteria.

2) In the second stage, the control strategy decides which vehicles should be charged in 'Without V2G' case if
Table 3 Applied limits to the control strategy for charging or discharging EVs at different hours during a day

\begin{tabular}{lll}
\hline Time of the day & Charging allowed? & Discharging allowed? \\
\hline 00:00-01:00 & Yes & Yes \\
01:00-02:00 & Yes & Yes \\
02:00-03:00 & Yes & Yes \\
03:00-04:00 & Yes & Yes \\
04:00-05:00 & Yes & Yes \\
05:00-06:00 & Yes & No \\
06:00-07:00 & No & No \\
07:00-08:00 & No & No \\
08:00-09:00 & No & No \\
09:00-10:00 & No & Yes \\
10:00-11:00 & Yes & Yes \\
11:00-12:00 & Yes & Yes \\
12:00-13:00 & Yes & Yes \\
13:00-14:00 & Yes & Yes \\
14:00-15:00 & Yes & No \\
15:00-16:00 & Yes & No \\
16:00-17:00 & Yes & No \\
17:00-18:00 & No & Yes \\
18:00-19:00 & No & Yes \\
19:00-20:00 & No & Yes \\
20:00-21:00 & No & Yes \\
21:00-22:00 & No & Yes \\
23:00-24:00 & Yes & Yes \\
\hline & & Yes \\
\hline
\end{tabular}

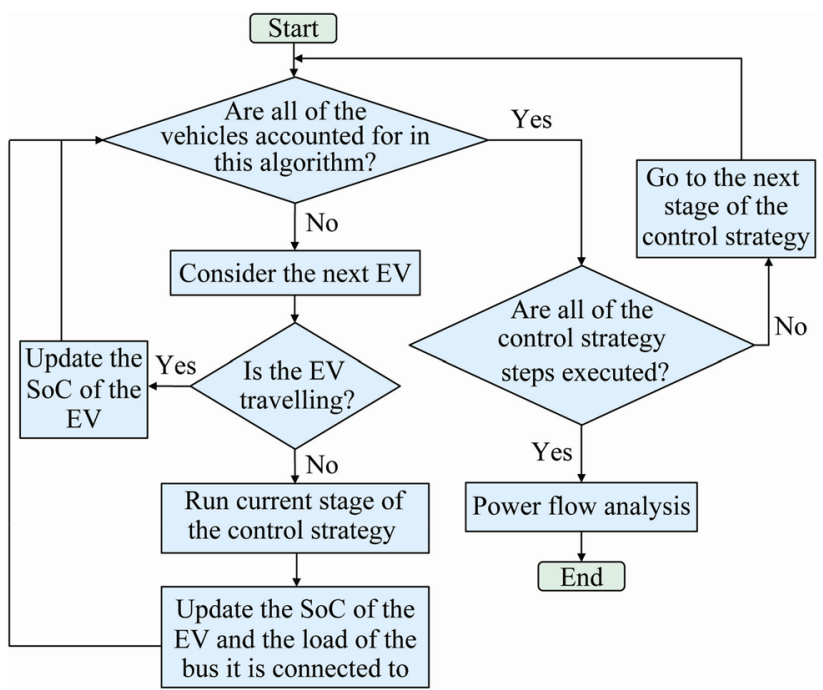

Fig. 2 Algorithm used at each time interval of the simulation

the vehicles are not being charged as a result of satisfying the above condition (No. 1). In this 'Without V2G' scenario, if the buying price of electricity at the current simulation time interval is lower than $60 \%$ of the maximum 


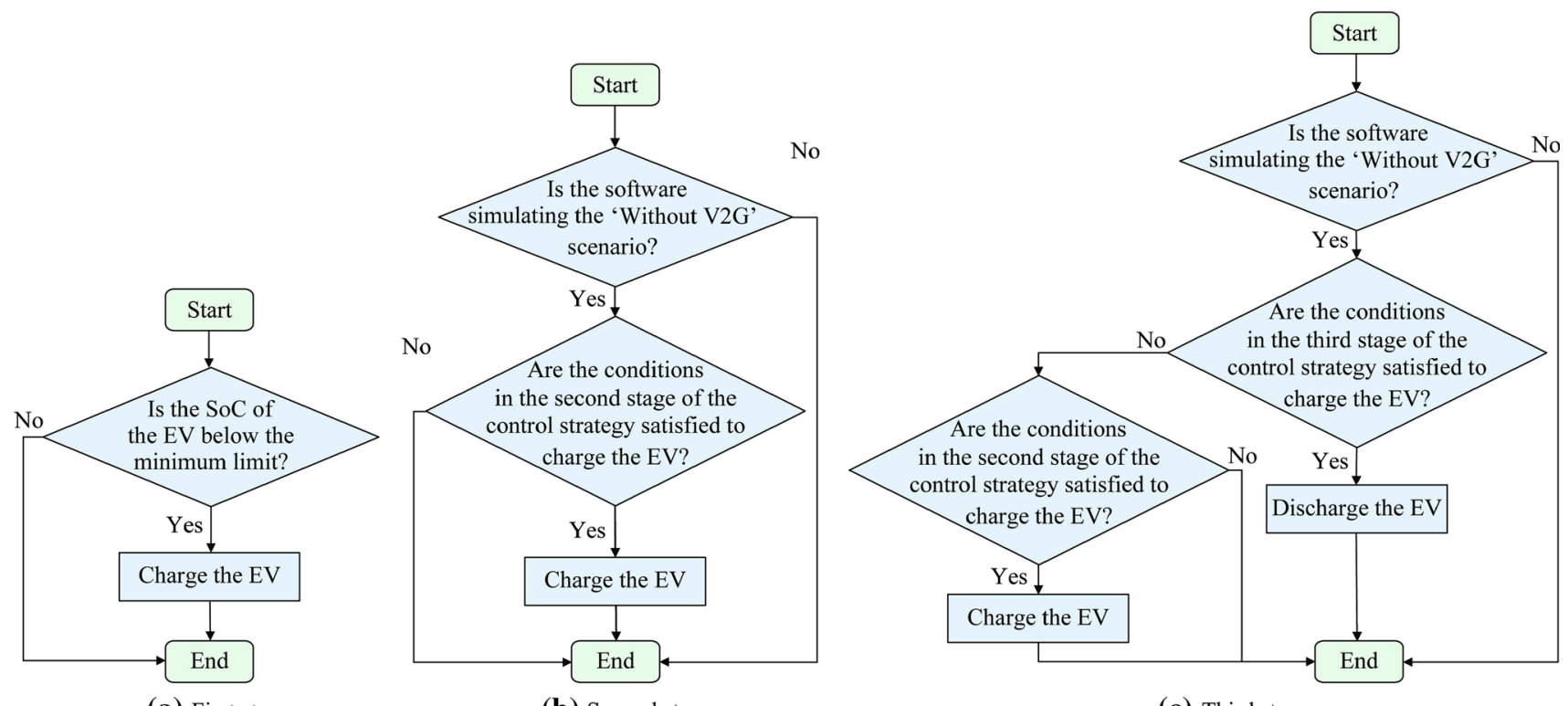

(a) First stage

(b) Second stage

(c) Third stage

Fig. 3 Three stages of the control strategy used in the V2G simulator algorithm

buying price of electricity during the day which is being simulated and SoC of the EV is below its maximum limit and charging is allowed at the current time of the day according to the choice of the user in Table 3, then the EV will be charged with nominal rate.

In other words, to charge the EVs in the 'Without V2G' scenario in the second stage of the control strategy, four conditions should be satisfied:

a) $L_{E V_{i}}$ should not be determined yet.

b) $b_{t}<\left(0.60 \times M a x \_b_{\text {day }}\right)$

c) $S o C_{E V_{i}}^{t}<M a x \_S o C_{E V_{i}}$

d) The limits in Table 3 allow charging.

where $L_{E V_{i}}$ is the load of the $i^{\text {th }} \mathrm{EV}$ at the current time interval in $\mathrm{kW}, b_{t}$ is the current buying electricity price in $£ / \mathrm{kWh}$, $M a x \_b_{d a y}$ is the maximum buying electricity price during the current day in $£ / \mathrm{kWh}$ and $M a x_{\_} S o C_{E V_{i}}$ is the maximum SoC limit of each $\mathrm{EV}$ in percentage. This effectively means that the control strategy tries to take advantage of the price fluctuation in the electricity market and minimize the charging cost of EVs within the system.

This stage of the control strategy will be executed for all of the vehicles in the 'Without V2G' scenario before the simulator executes the next stage.

3) In the third stage of the control strategy, the simulator decides which vehicles should be charged or discharged in the 'With V2G' scenario if the vehicles are not being charged as a result of satisfying condition a) due to their SoC being below the minimum SoC limit. In this stage, if the current selling price of electricity is higher than $80 \%$ of the maximum selling price of electricity during the day being simulated, and the $\mathrm{SoC}$ of the vehicle is above its minimum limit plus $10 \%$ and discharging is allowed at this time of the day according to the choice of the user in Table 3, then the EV will be discharged into the grid at the nominal rate $(3 \mathrm{~kW})$. The $10 \%$ deadband applied to the SoC is used to avoid excessive charge/discharge cycles and prevent conditions where the EV will be discharged while its battery $\mathrm{SoC}$ is close to its minimum limit.

In other words, to discharge the vehicles in this stage of the control strategy, four conditions should be satisfied in the 'With V2G' scenario:

1) $L_{E V_{i}}$ should not be determined yet.

2) $s_{t}>\left(0.80 \times M a x \_s_{d a y}\right)$.

3) $S o C_{E V_{i}}^{t}>\left(M i n \_S o C_{E V_{i}}+10\right)$.

4) The limits in Table 3 allow discharging.

where $s_{t}$ is the current selling price of electricity in $£ / \mathrm{kWh}$ and Max_s $s_{d a y}$ is the maximum selling electricity price during the current day in $£ / k W h \quad M i n \_S o C_{E V_{i}}$ is the minimum SoC limit of the $i^{\text {th }} \mathrm{EV}$ in percentage.

The simulator checks whether each EV can sell electricity before trying to check whether it can buy electricity because selling electricity has priority in this control strategy. This means that if an EV is not able to sell electricity, the control strategy then checks whether it can buy electricity in 'With V2G' scenario. The conditions used to charge an EV at this stage of the control strategy are the same as the conditions mentioned in the second stage of this control strategy. 
Table 4 The nominal share of non-EV loads on different busses of the IEEE30 network

\begin{tabular}{lcll}
\hline Bus number & $\begin{array}{l}\text { Nominal load } \\
\text { (MW) }\end{array}$ & Bus number & $\begin{array}{l}\text { Nominal load } \\
\text { (MW) }\end{array}$ \\
\hline 1 & 0 & 16 & 3.5 \\
2 & 21.7 & 17 & 9 \\
3 & 2.4 & 18 & 3.2 \\
4 & 7.6 & 19 & 9.5 \\
5 & 0 & 20 & 2.2 \\
6 & 0 & 21 & 17.5 \\
7 & 22.8 & 22 & 0 \\
8 & 30 & 23 & 3.2 \\
9 & 0 & 24 & 8.7 \\
10 & 5.8 & 25 & 0 \\
11 & 0 & 26 & 3.5 \\
12 & 11.2 & 27 & 0 \\
13 & 0 & 28 & 0 \\
14 & 6.2 & 29 & 2.4 \\
15 & 8.2 & 30 & 10.6 \\
\hline
\end{tabular}

Essentially, at this third stage the control strategy tries to take advantage of the price fluctuation in the electricity market and minimize the charging cost of vehicles and also if possible earn some money for the owner by selling electricity back to the grid during high electricity prices.

In this control strategy all of the vehicles have the same chance to be charged or discharged because the electricity price is the same for all of them. In addition, in the 'With V2G' scenario, it is possible that the control strategy creates a situation where some of the EVs will be discharged to provide power for the charging vehicles. This could be beneficial in cases that the charging and discharging EVs are connected to a substation which is loaded close to its capacity limit.

\subsection{Load profile and electricity price}

To start the analysis the simulator needs two more sets of data which are 'non-EV load profile' and 'electricity price data'. To simulate the impact of EVs over five working days (weekdays), the demand profile recorded in the UK from Monday, $7^{\text {th }}$, to Friday, 11th of October 2013 [18] with 10 minute resolution is scaled down to match the IEEE30 network load scale (nominal demand of 189.2MW).

The share of the non-EV loads on each bus of the network is equal to the proportion of loads defined in the IEEE30 standard load profile, shown in Table 4. The total demand profile (without the load of EVs) used in the simulation is shown in Fig. 4.

The active power which is produced from each generator in the IEEE30 model is also scaled to match the

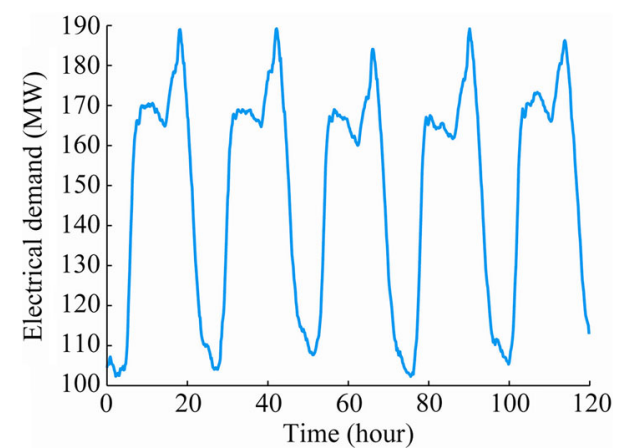

Fig. 4 UK electricity demand profile without EV loads over five weekdays (scaled down to match the IEEE30 demand scale)

Table 5 Nominal generation capacity of the power plants used in the IEEE30 network

\begin{tabular}{ll}
\hline Bus number & Generation capacity (MW) \\
\hline 1 & 23.54 \\
2 & 60.97 \\
13 & 37.00 \\
22 & 21.59 \\
23 & 19.20 \\
27 & 26.91 \\
\hline
\end{tabular}

change in non-EV load demand during the simulation. The share of the active power from each generator is equal to the proportion of active power generation defined in the IEEE30 standard model [14] which is shown in Table 5.

The other loads (non-EV loads) within the system were assumed to be constant during each simulation time interval. Such requirement of constant voltage and power, over a fixed time interval is necessary to run the load flow analysis of the power system.

Figure 5 shows the selling and buying electricity prices used during the simulation [19]. It is assumed that the selling and buying electricity prices for all the simulation days are equal to the prices of electricity on 12th of November 2013 in the UK. The original price data with 30 minute resolution was converted to data with 10 minute resolution to be used in the simulation.

\section{Simulation results}

At the beginning of the simulation the simulator allocates a pattern of travel for each EV. As an example, Table 6 presents the location of EV No. 1 during the first day of the simulation. During the following days this vehicle repeats this travel pattern.

As mentioned, there are $5000 \mathrm{EVs}$ within the system and each one has a storage capacity of $60 \mathrm{kWh}$, meaning a total storage capacity of $300 \mathrm{MWh}$. In this simulation, the EVs 


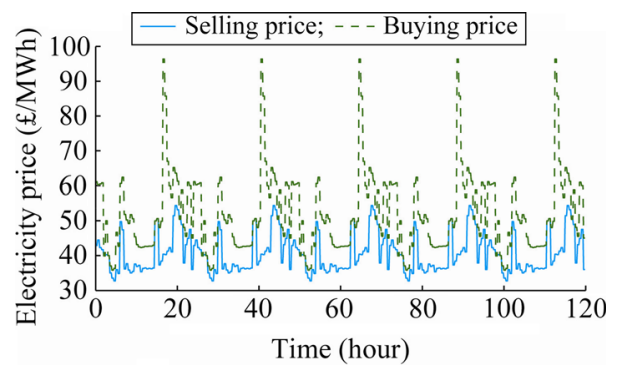

Fig. 5 Electricity selling and buying price used in the simulation

Table 6 Location of EV No. 1 during the first day of simulation

\begin{tabular}{lll}
\hline Time of the day & Location & Bus number \\
\hline 00:00-07:30 & Home & 25 \\
07:30-08:20 & Travelling from home to work & N/A \\
08:20-16:20 & Work & 28 \\
16:20-17:10 & Travelling back from work to home & N/A \\
17:10-24:00 & Home & 25 \\
\hline
\end{tabular}

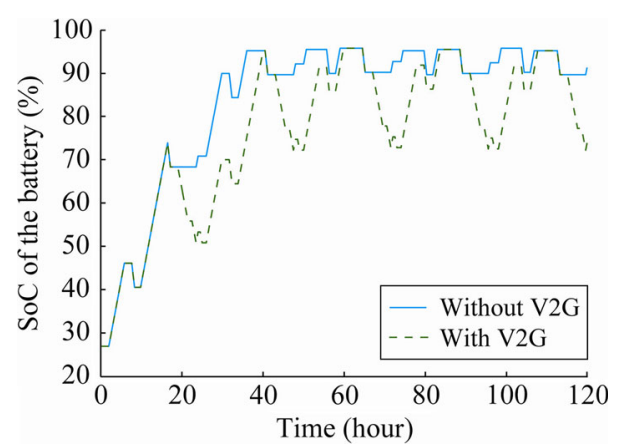

Fig. 6 SoC\% of the EV No. 1 during the simulation

need 41.6 MWh energy in total to satisfy the daily travel requirements of their owners, so about $86 \%$ of the aggregate energy storage capacity of the EV batteries will be unused by the owners, and it could be utilised for the V2G participation.

After applying the control strategy to the system, the simulator determines the way that each EV is charged or discharged during the simulation. Fig. 6 shows the SoC (\%) of the batteries of EV No. 1 in both 'Without V2G' and 'With V2G' scenarios during the simulation. As mentioned, the system controller always tries to ensure that the EV batteries have sufficient energy to complete the next journey successfully. When the vehicle is parked and is not being charged or discharged, the SoC of the EV batteries does not change, i.e. self-discharging is neglected. The SoC increases when the EV is being charged and decreases when the EV delivers power back to the grid or when it is traveling.

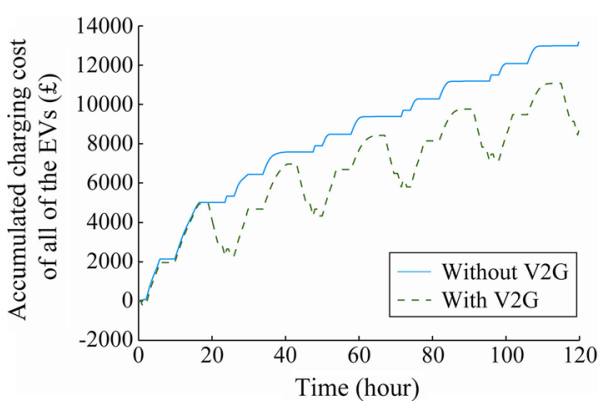

Fig. 7 Aggregate accumulated charging cost of all of the EVs within the system during the simulation

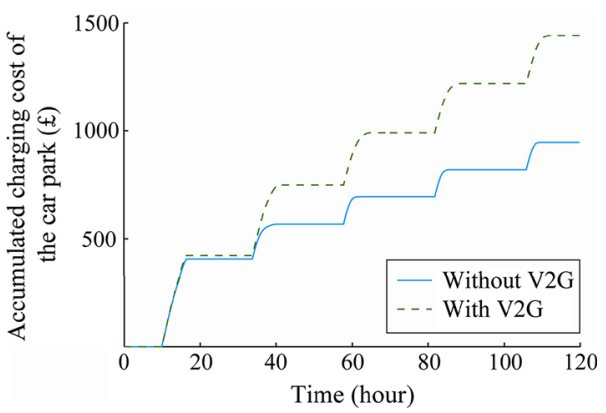

Fig. 8 Accumulated charging cost of the car park located on bus 11

As shown in Fig. 6, in 'With V2G' scenario, the SoC of this vehicle battery changes within a wider range in comparison to the 'Without V2G' scenario as the EV is being controlled to discharge the energy stored in its batteries back to the grid in some occasions. This extra fluctuation of the SoC of the batteries due to participating in V2G scheme could potentially degrade the performance of batteries as discussed in [20-23]. This issue will be investigated in future work with an attempt to optimize the profit gained from V2G participation of these EVs.

The following equation is used to find the total accumulated cost of charging all the EVs in British pound ( $(\mathfrak{)}$ up to time interval $T$ while considering the amount of money they earn due to selling electricity.

$P=\sum_{t=1}^{T} \sum_{i=1}^{N}\left(L_{E V_{i}} \times \delta \times x_{t}\right)$

where $t$ is the time interval (i.e. each one represents 10 $\min$ ); $T$ is the time interval that the accumulated charging cost will be calculated up to that point; $i$ is the EV tag number; $N$ is the total number of EVs, and $x_{t}$ is the trade price of electricity at time interval $t$ in $£ / \mathrm{kWh}$ which is equal to selling or buying electricity price if the car is selling or buying electricity, respectively.

The final saving of the 'With V2G' scenarios in British pound $(\mathfrak{E})$ is found from the following equation which considers the difference between the SoC of the EV batteries in the 'With V2G' and 'Without V2G' scenarios at 
Table 7 Accumulated extra charging cost of the car parks in the 'With V2G' scenario at the end of the simulation in comparison to the 'Without V2G' scenario

\begin{tabular}{|c|c|c|}
\hline Car park number & Extra cost $(\mathfrak{E})$ & Extra cost $(\%)$ \\
\hline 1 & 914.28 & 52.35 \\
\hline 2 & 496.76 & 52.57 \\
\hline 3 & 361.08 & 53.18 \\
\hline 4 & 1039.16 & 52.80 \\
\hline
\end{tabular}

Table 8 Impact of changing the limits in the control strategy on the aggregate charging costs in the 'With V2G' scenario at the end of the simulation in comparison to the 'Without V2G' scenario

\begin{tabular}{lcc}
\hline $\begin{array}{l}\text { Selected limits }(\%) \\
\text { (upper and lower limits) }\end{array}$ & $\begin{array}{l}\text { Cost reduction } \\
(\mathfrak{f})\end{array}$ & $\begin{array}{l}\text { Cost reduction } \\
(\%)\end{array}$ \\
\hline 80,70 & 1576.05 & 10.26 \\
80,60 & 1799.77 & 13.63 \\
80,50 & 1726.12 & 13.44 \\
80,40 & -241.914 & -3.19 \\
80,30 & -234.74 & -3.21 \\
80,20 & -234.74 & -3.21 \\
80,10 & -234.74 & -3.21 \\
70,50 & 71.85 & 0.55 \\
60,40 & -1548.63 & -20.42 \\
50,30 & -989.79 & -13.55 \\
40,20 & -989.79 & -13.55 \\
\hline
\end{tabular}

the end of the simulation. It is assumed that at the end of the simulation the EVs in the 'With V2G' scenario use the electricity with the average buying price to charge their batteries until they reach the $\mathrm{SoC}$ of their corresponding EV batteries in the 'Without V2G' scenarios.

$$
\begin{aligned}
S= & P_{\text {without }}-P_{\text {with }}-\frac{C \times \bar{P}_{\text {buy }}}{100} \\
& \times \sum_{i=1}^{N}\left(S o C_{E V_{i}, \text { without }}^{\text {final }}-S o C_{E V_{i}, \text { with }}^{\text {final }}\right)
\end{aligned}
$$

where $S$ is the amount of aggregate saving at the end of the simulation made by all of the EVs participating in $\mathrm{V} 2 \mathrm{G}$ in comparison to the 'Without V2G' scenario in British pound (£); $P_{\text {without }}$ is the cost of charging EVs in the 'Without V2G' scenario in British pound ( $\mathfrak{f})$; $P_{\text {with }}$ is the cost of charging EVs in the 'With V2G' scenario in British pound (f) after subtracting the amount of money they earn as a result of selling electricity back to the grid, $\bar{P}_{b u y}$ is the average buying price of electricity during the simulation in $£ / \mathrm{kWh} ; S_{o} C_{E V_{i}, \text { without }}^{\text {final }}$ is the SoC of the $i^{\text {th }} \mathrm{EV}$ at the end of the simulation in percentage in the 'Without V2G' scenario; and $\mathrm{SoC}_{E V_{i} \text {,with }}^{\text {final }}$ is the SoC of the $i^{\text {th }} \mathrm{EV}$ at the end of the simulation in percentage in the 'With V2G' scenario.
The accumulated charging cost of all of the EVs within the system in both 'Without V2G' and 'With V2G' scenarios during the simulation calculated using (3) is shown in Fig. 7. Due to applying the control strategy some vehicles were able to sell electricity to the grid during high electricity prices in 'With V2G' scenario, so the accumulated charging cost of the EVs participating in $\mathrm{V} 2 \mathrm{G}$ is lower than the vehicles in 'Without V2G' scenario. By using (4), it can be concluded that at the end of the fifth day of the simulation the EVs participating in V2G saved $£ 1800$, which is $13.6 \%$ of the total cost of charging of all of the EVs in the 'Without V2G' scenario.

Figure 8 shows the accumulated charging cost of car park 2 located on bus 11 in both 'With V2G' and 'Without V2G' scenarios. This figure is obtained by using (3) and taking the load of each EV equal to zero $\left(L_{E V_{i}}=0\right)$ if it is not inside this car park at any time interval. When the car park is empty (all of the EVs are parked at home or are travelling), the value of accumulated charging cost does not change.

Figure 8 shows that the accumulated aggregate charging cost of the EVs when they were inside this car park (after subtracting the profit they earn from selling electricity) was $52 \%$ higher in the 'With V2G' scenario. It happens because the vehicles tend to charge when their owners are at work (the car is inside the car park) due to lower electricity price during that time. This means that despite EVs save costs by participating in $\mathrm{V} 2 \mathrm{G}$, the car parks cannot make any profit from the applied control strategy. Table 7 shows the amount of financial loss of all of the car parks within the system as a result of the EVs participating in the V2G scheme. Apparently, all of the car parks should pay around $52 \%$ more for the cost of charging of their EVs if those EVs are participating in $\mathrm{V} 2 \mathrm{G}$ scheme in comparison to the 'Without V2G' scenario.

However, it does not mean that the use of car parks or EV aggregators in future will be without any advantage because they might provide some other services, such as frequency regulation or 'firming' renewable power, and make some profit by participating in such demand side management or $\mathrm{V} 2 \mathrm{G}$ schemes.

As the price of electricity in the power system reflects the cost of generation, the control strategy used could also lead to a reduction in the cost of electricity generation by reducing the stop/start cycles of power plants.

It should also be noted that if the number of the EVs adopting this control strategy becomes significant, the price of electricity might change with the total demand profile within the power system.

The upper and lower limits of $80 \%$ and $60 \%$ in the control strategy were selected randomly in the initial simulation. However, to compare the results of the simulations due to different value selection for these limits, 
the values shown in Table 8 are applied to the control strategy, and the results are also presented. Initially the discharging limit is kept constant at $80 \%$ and the charging limit is reduced from $70 \%$ down to $10 \%$ with the step of $10 \%$. Then both of the limits are reduced with the step of $10 \%$, but the gap between them is kept constant at $20 \%$. The best financial profit is achieved by choosing the values of $80 \%$ and $60 \%$ for the limits in the control strategy. Decreasing or increasing the lower limit from $60 \%$, decreases the total financial gain from participation of EVs in the V2G scheme. In addition, reduction of the upper limit from $80 \%$ while keeping its difference with the lower limit at $20 \%$ does not improve the financial profit from V2G operation. The worst case is observed when the values of $60 \%$ and $40 \%$ for the upper and lower limits are selected respectively. In that case, participation of $\mathrm{EVs}$ in the $\mathrm{V} 2 \mathrm{G}$ scheme causes an additional $20.4 \%$ increase in the aggregate charging costs of all EVs.

\section{Conclusions}

EVs can not only be used for clean transport, but also could be utilized as a responsive load or generator to improve the performance and efficiency of the power system. On average, EVs are parked a significant amount of time during a typical day and have an energy storage capacity which is usually more than the regular requirement of their owners.

In this paper, the potential financial saving from participation of EVs in a V2G scheme has been investigated. A simulator has been developed within the MATLAB environment by the authors to model a standard IEEE30 power system with 5000 EVs. The utilization of EVs as energy storage devices to take advantage of the difference between selling and buying electricity prices was modelled using a novel dispatching strategy to control the charging and discharging of the EVs. The control strategy considered the electricity prices, the EV capacity, the SoC, vehicle movement within the system and the requirements of driver and power system operator.

The results from two scenarios of 'Without V2G' and 'With V2G' show that if the electrical demand and generation of the EVs are controlled appropriately with the proposed control strategy, the EVs in the 'With V2G' scenario can potentially save $13.6 \%$ on charging costs in comparison to the 'Without $\mathrm{V} 2 \mathrm{G}$ ' scenario due to discharging their excess stored energy back to the grid during the time of high electricity price. Therefore, participating in V2G schemes can reduce the cost of owning an electric vehicle, further encouraging their adoption.

Future work will focus on the impact of EVs on the low voltage distribution network with a control strategy to minimize the voltage deviation and avoidance of feeder and substation capacity limits. In addition, the utilisation of the aggregate battery storage capacity of EVs to offer the support for power grid, such as frequency regulation and 'firming' of renewable generation will also be studied.

Acknowledgment This work is a part of the Battery Characterisation and Management (BaChMan) project funded by the Engineering and Physical Sciences Research Council (EPSRC) in the UK and National Natural Science Foundation of China (NSFC) (grant reference: EP/L001004/1).

Open Access This article is distributed under the terms of the Creative Commons Attribution 4.0 International License (http:// creativecommons.org/licenses/by/4.0/), which permits unrestricted use, distribution, and reproduction in any medium, provided you give appropriate credit to the original author(s) and the source, provide a link to the Creative Commons license, and indicate if changes were made.

\section{References}

[1] Sierzchula W, Bakker S, Maat K, van Wee B (2014) The influence of financial incentives and other socio-economic factors on electric vehicle adoption. Energy Policy 68:183-194

[2] Green Ii RC, Wang L, Alam M (2011) The impact of plug-in hybrid electric vehicles on distribution networks: a review and outlook. Renew Sustain Energy Rev 15:544-553

[3] Wang J, Liu C, Ton D, Zhou Y, Kim J, Vyas A (2011) Impact of plug-in hybrid electric vehicles on power systems with demand response and wind power. Energy Policy 39:4016-4021

[4] Kempton W, Tomić J (2005) Vehicle-to-grid power implementation: from stabilizing the grid to supporting large-scale renewable energy. J Power Sour 144:280-294

[5] Fernandez LP, Roman TGS, Cossent R, Domingo CM, Frias P (2011) Assessment of the impact of plug-in electric vehicles on distribution networks. IEEE Trans Power Syst 26:206-213

[6] Clement-Nyns K, Haesen E, Driesen J (2011) The impact of vehicle-to-grid on the distribution grid. Electr Power Syst Res 81:185-192

[7] Clement-Nyns K, Haesen E, Driesen J (2010) The impact of charging plug-in hybrid electric vehicles on a residential distribution grid. IEEE Trans Power Syst 25:371-380

[8] Ma Y, Houghton T, Cruden A, Infield D (2012) Modeling the benefits of vehicle-to-grid technology to a power system. IEEE Trans Power Syst 27:1012-1020

[9] Zhong F (2012) A distributed demand response algorithm and its application to PHEV charging in smart grids. IEEE Trans Smart Grid 3:1280-1290

[10] Di W, Aliprantis DC, Lei Y (2012) Load scheduling and dispatch for aggregators of plug-in electric vehicles. IEEE Trans Smart Grid 3:368-376

[11] Jinbiao X, Wong VWS (2011) An approximate dynamic programming approach for coordinated charging control at vehicleto-grid aggregator. Paper presented at IEEE international conference on smart grid communications (SmartGridComm), 17-20 Oct 2011

[12] Tomić J, Kempton W (2007) Using fleets of electric-drive vehicles for grid support. J Power Sour 168:459-468

[13] Sekyung H, Soohee H, Sezaki K (2010) Development of an optimal vehicle-to-grid aggregator for frequency regulation. IEEE Trans Smart Grid 1:65-72 
[14] Alsac O, Stott B (1974) Optimal load flow with steady-state security. IEEE Trans Power Appar Syst, 93: 745-751

[15] Zimmerman RD, Murillo-Sanchez CE, Thomas RJ (2009) MATPOWER's extensible optimal power flow architecture. Paper presented at IEEE Power \& Energy Society General Meeting, PES '09, 26-30 July 20092009

[16] The Scottish Government website (2010) http://www.scotland. gov.uk/Topics/Statistics/Browse/Transport-Travel/PubTravScot Res. Accessed 14th June 2012

[17] Tesla Motors website (2014) http://www.teslamotors.com/. Accessed 22 April 2014

[18] GridWatch Database (2014) http://www.gridwatch.templar.co. uk/download.php. Accessed 19 Aug 2014

[19] The Balancing Mechanism Reporting System (BMRS) website (2013) http://www.bmreports.com/bsp/SystemPricesHistoric. htm. Accessed 9 Sept 2014

[20] Zhang Y, Wang CY, Tang X (2011) Cycling degradation of an automotive LiFePO4 lithium-ion battery. J Power Sour 196:1513-1520

[21] Broussely M, Biensan P, Bonhomme F, Blanchard P, Herreyre $\mathrm{S}$, Nechev $\mathrm{K}$ et al (2005) Main aging mechanisms in $\mathrm{Li}$ ion batteries. J Power Sour 146:90-96

[22] Peterson SB, Apt J, Whitacre JF (2010) Lithium-ion battery cell degradation resulting from realistic vehicle and vehicle-to-grid utilization. J Power Sour 195:2385-2392

[23] Deshpande R, Verbrugge M, Cheng YT, Wang J, Liu P (2012) Battery cycle life prediction with coupled chemical degradation and fatigue mechanics. J Electrochem Soc 159:A1730-A1738
Electrical Engineering from the University of Strathclyde in 2014. He is currently a research fellow in the Energy Technology group at the University of Southampton, U.K., and he studies the impact of charging/discharging EVs on the performance of the electrical grid and EV batteries.

Andrew CRUDEN received the B.Eng. degree in electronic and electrical engineering, a M.Sc. degree in electrical power engineering, and the Ph.D. degree in optical current sensing from the University of Strathclyde, Glasgow, U.K. Since 2012, he has been Professor of Energy Technology at the University of Southampton, U.K. His current research interests include electrical energy storage, where he is Co-Director of the UK Centre for Doctoral Training in 'Energy Storage and its Applications' (www.energystorage-cdt.ac.uk), investigation of vehicle-to-grid energy storage of aggregated electric vehicles, and a member of the EPSRC Supergen consortium on Energy Storage, called 'SuperStore'.

Suleiman SHARKH obtained his BEng and $\mathrm{PhD}$ degrees in Electrical Engineering from the University of Southampton in 1990 and 1994, respectively. He is currently Professor of Power Electronics, Machines and Drives and Head of the Electro-Mechanical Research Group at the University of Southampton. He is also the Managing Director of HiT Systems Ltd, and a visiting Professor at Beijing Jiaotong University. He has 20 years research experience in the field of electrical and electromagnetic systems including electric switches, power electronics, electrical machines, control systems and characterization and management of advanced batteries.

Mahdi KIAEE received the BSc degree in Electrical/Control Engineering from Iran University of Science and Technology in 2006. He also received the MSc degree in Control Systems in 2008 from the University of Sheffield and the $\mathrm{PhD}$ degree in Electronic and 